\title{
An IT Project as a Plaything of its Organizational Environment - Long-Term Challenges in Financial Services
}

by

Olga Bürger, Gilbert Fridgen, Dominikus Kleindienst, Jonas Manderscheid, Tirazheh Zare Garizy

appears in: Journal of Information Technology Teaching Cases, 2016 
Teaching Case

\title{
An IT Project as a Plaything of its Organizational Environ- ment - Long-Term Challenges in Financial Services
}

\begin{abstract}
At the end of 2015, and after 10 years, the German financial service provider FinAdvizard finally achieved the first results from the development project of its next-generation advisory application. Although this achievement can be considered as project success, the new application includes only the core of the initially intended scope because of environmental changes. First, the project team had to continuously deal with resource scarcity, stakeholder influences, regulatory requirements, and the involvement of its sales force. The team also had to adapt different management approaches and software development methods. Furthermore, the organization's focus and management attention repeatedly changed over time. Subsequently, this case retrospectively highlights information technology (IT) project management issues and challenges faced by large software development projects. Given the longitudinal analysis of the period of a decade, both positive and negative effects that are not visible in shorter IT projects become apparent. Additionally, the case sheds light and stimulates a discussion on, among others, collaboration between the business and IT departments, the importance of top IT management support, the challenge of bimodal or two-speed IT, and the influence of a strong sales force.
\end{abstract}

Keywords: financial advisory, software development, IT management, project management. 